Journal of Dairy Research (2002) 69 343-344. (C) Proprietors of Journal of Dairy Research 2002

\title{
Obituary
}

\section{Dr Brian A. Rolls}

Readers will be sorry to hear that Brian Rolls died on 24 March 2002 after a heart attack. Brian was Senior Editor of this Journal for over 11 years (1989-2000). Many authors will remember the correspondence they had with him, in which he always tried to be constructive and courteous, helping authors to present their results clearly and to extract all the conclusions to which they led. In addition, he always edited the papers so that printing deadlines were met and the issues went out on time. During his editorship the reputation of the Journal was steadily enhanced, as measured by citations. He certainly deserved what he achieved with the Journal, as he always worked as hard as he thought necessary, often spending a day or more editing a single paper. His aim was to make sure the results contained in it were presented effectively so that readers could draw the conclusions easily.

Brian was educated at Bournemouth Grammar School and Downing College, Cambridge, where he studied chemistry. He took a First Class Honours degree from Cambridge University in 1962. Then he spent 4 years at the Atomic Energy Authority at Harwell, where he worked on the structure of reverse osmosis membranes. In 1967, he transferred to the Nutrition Department of the National Institute for Research in Dairying at Shinfield, Reading, initially studying protein digestion and absorption. This work led to a Ph.D. from the University of Reading in 1970. Then he spent a few years studying the influence of intestinal bacteria on the nutrition of the host and the physiology of the gut. Later he became interested in dietary and environmental factors that influenced milk composition and nutritional quality. Obesity was then becoming a serious health problem in Western countries and it was of great interest to question the extent to which a mother's nutrition as well as her degree of overweight could influence the composition of her milk and the subsequent development of her offspring. Brian designed an ingenious experiment (he loved experimental design and was skilled in introducing practical solutions to problems encountered in experimental nutrition) to examine the effects of maternal diet and maternal body fat content in rats during pregnancy and lactation, on milk composition. He was able to show that maternal nutrition in lactation profoundly influences milk composition and that these influences were markedly modified by pre-existing maternal obesity and diet during pregnancy. The main effects on milk composition were a reduction in the proportion of the characteristic medium chain length fatty acids as a result of high fat diets and obesity. Such changes would be expected to modify the patterns of fat absorption in the offspring.

But Brian was not particularly ambitious to further his career in research and his major contribution was probably the use of his writing skills to bring scientific concepts to a wider readership. He contributed reviews to books and journals and also edited a number of books as well as the Journal of Dairy Research. He really found his niche as an editor, which role was enhanced by his clear and concise prose style and his penetrating thinking. He also had a wicked sense of humour, on one occasion quoting Samuel Johnson to his Head of Department: "Sir, I thank you for your interesting and innovative manuscript. Unfortunately, the parts that are interesting are not innovative and the parts that are innovative are not new".

Brian was not only a scientist, but also a well-rounded man with many interests. 
From a boy until his death he was intensely interested in science fiction, building a large library and an encyclopaedic knowledge of this subject. He even had a novel, "Something in Mind", published in the late 60s. It may be that his interest in science fiction led him towards a scientific career.

Brian was also a family man. Despite his scientific and editorial responsibilities, he always had time to guide and support his two sons and two daughters and, more latterly, to play with his two grandchildren. He enjoyed holidays with his wife, in recent years particularly in the north-west of Scotland, walking in the hills, forests and valleys with the family dog.

I will always remember Brian particularly for his kindness and support (he always found time to talk, help with problems and contribute ideas) and for his judgement and dry sense of humour. Working with him was always a pleasure, and he never demanded more effort than he was prepared to contribute himself. From a professional viewpoint, I think his main legacy must be found among his editorial achievements, which helped to convey and extend knowledge of both nutritional findings and dairy science. He will be greatly missed by all who knew him - his family and friends, his former colleagues and the wider scientific community.

Dr Margaret Green

Bradfield, May 2002 